\title{
The Relationship Between Attachment Styles, Emotion Regulation and Psychopathology Symptoms in Turkish and American Students
}

\author{
Sevginar Vatan \\ Hacettepe University, Ankara, Turkey
}

\author{
John Pellitteri \\ City University of New York, New York, USA
}

\begin{abstract}
Two samples of university students, one from Turkey and the other from the USA, were compared on measures of attachment styles, difficulties in emotional regulation and self-reported symptoms of psychopathology. Results indicated that for both samples the level of anxiety in attachment and the lack of strategies in emotional regulation predicted several symptoms of psychopathology. Differences emerged in demographic predictors with parents' educational level predicting many of the symptoms in the Turkish population while age was the major demographic predictor in the USA sample. The results suggest that attachment and emotional regulation are universal personality factors contributing to psychopathology across cultures. The collectivistic cultural framework of the Turkish sample showed greater significance to family factors in contrast to the individualistic cultural influences in the USA sample.
\end{abstract}

Keywords: attachment, emotional regulation, psychopathology, cross-cultural

Psychopathology is multi-faceted and the determination of its predictors allows for early identification of symptoms, treatment, and prevention. Two major factors that have been related to psychopathology are the capacity for emotional regulation and attachment style (Dozier, Stovall-McClough, \& Albus, 2008; Gross, 2014). Manifestations of psychopathology are characterized by disturbances in numerous processes (i.e., attention, cognition, behavior) including dysfunctional emotional processes which are impacted by, and contribute to, difficulties in regulating emotions (Kring, 2008). Insecure attachment styles, formed in childhood, set patterns of maladaptive strategies for maintaining relationships with others that involve the regulation of emotional distress (Dozier et al., 2008). The cross cultural examination between Turkish and USA university students in this current study considers the distinctions and similarities in how these factors predict symptoms of psychopathology across diverse cultural frameworks.

In the last two decades, there has been increased attention to emotion regulation and its positive relation with mental health (Campbell-Sills, Ellard, \& Barlow, 2014; Joormann \& Seimer, 2014; Mullin \& Hinshaw, 2007), as well as other factors such as stress-related disease (Appleton \& Kubzansky, 2014; Chen \& Miller, 2014), health behavior (Deifenbach, Miller, Porter, Peters, Stefanek, \& Leventhal, 2008), relationship satisfaction (Levenson, Haase, Bloch, Holley, \& Seider, 2014), and work performance (Diefendorff, Hall, Lord,

\footnotetext{
Sevginar Vatan, Department of Psychology, Hacettepe University.

John Pellitteri, Ph.D., Associate Professor, Department of Educational \& Community Programs, Queens College, City University of New York.
} 
\& Strean, 2000). Emotional regulation is central to numerous areas of psychosocial functioning (Gross \& Thompson, 2007) and therefore is a necessary factor in understanding the psychological dysfunctions that lead to psychopathology. Mechanisms of regulation emphasize the control of emotional experiences, the expression of emotion and strategies to decrease negative emotional arousal (Garner \& Spears, 2000). Campbell-Sills and Barlow (2007) describe how anxiety and mood disorders for example, can be conceptualized by difficulties in various regulatory deficits such as "problematic use of situation selection, situation modification, attentional deployment, cognitive change and response modulation to regulate emotions" (p. 545).

Attempts to control emotional experience and expression through avoiding internal feelings for example, (which is aligned with avoidant attachment styles), can inordinately increase physiological arousal (Gross \& Levenson, 1997). Maladaptive strategies in managing arousal can adversely impact cognitive processes and behavioral patterns that, once ingrained, can produce symptoms of psychopathology. Gratz and Roemer (2004) note other functions of emotional regulation such as satisfying hedonic needs, supporting specific goal pursuits, facilitating the global personality system and controlling impulsivity. Difficulties in generating and regulating positive emotions and in maintaining motivation toward goals of optimal well-being are also emotional regulation deficits that are implicated in psychopathology.

Attachment theory (Bowlby, 1982; Cassidy \& Shaver, 2008) offers frameworks for understanding how internalized working models of relationships affect the development of self. Mental representations of the self and beliefs in the availability of significant others influences cognitive appraisals of personal and interpersonal experiences and creates patterns emotional and behavioral functioning that underscore well-being and mental health (Bretherton \& Munholland, 2008). Secure and insecure attachment styles have been associated with mental health and psychopathology respectively. Attachment styles have been studied in relationship to psychopathology in children and adults (DeKlyen \& Greenberg, 2008; Dozier et al., 2008; Mikulincer \& Shaver, 2007), psychotherapy (Leiberman \& Zeanah, 1999; Slade, 2008), couples and family therapy (Byng-Hall, 1999; Johnson, 2008), adolescent development (Allen, 2008) and adult romantic relationships (Feeney, 2008).

The direct connection between attachment styles and emotional regulation processes has been described (Mikulincer \& Shaver, 2008; Shaver \& Mikulincer, 2014). Intense emotions such as fear or anxiety will be aroused in response to psychological threat (i.e., abandonment, rejection). In such moments, an individual's attachment system is activated usually leading to the primary attachment strategy which is seeking proximity to a stable and supportive attachment figure (Main, 1990). The security from an attachment figure can be in the form of a real person or an internalized mental representation (i.e., image, memory, schema) from a past or current relationship (Mikulincer \& Shaver, 2008). The absence of a real or internalized attachment figure and/or the uncertainty of such a figure's availability for support will increase the intensity of emotions thus leading to a greater need for emotional regulation.

Secondary attachment strategies involve the hyper-activation or the deactivation of attachment behaviors and correspond to Anxious and Avoidant insecure attachment styles respectively. Insecure attachment strategies have been described "along the dimension of attempts to minimize or maximize the expression of attachment needs" (Dozier et al., 2008, p. 718) and are related respectively to externalizing and internalizing clinical disorders due to the direction of attention away or toward conflicted emotional states in the self and caregiver relationship. The Avoidant and Anxious attachment styles involve strategies to regulate emotions through dismissive or preoccupied focus on internal affect. 
Unlike individuals with secure attachments who are generally capable of reducing anxiety and feeling safe in response to threats, insecurely attached individuals must contend with greater emotional arousal, a relatively more extensive history of unavailable attachment figures, and less effective strategies for attaining security. Feldman-Barrett, Wilson-Mendenhall, and Barsalou (2014) consider psychopathology and its related emotional dysregulation as resulting from "entrenched conceptualizations that are overly ritualized and not sufficiently situation-specific" (p. 459) which would include the conceptualizations of self and others that form the basis of internal working models.

Culture plays an important role in the development of personality and social relationships and by extension the signs and symptoms of psychological disorders. While noting universals in developmental goals, cultural factors determine the type and degree of deviations that set the criteria for psychopathology (Pennington, 2002). As a collective system of meaning-making, culture influences the experience and interpretation of emotions (Shweder, Haidt, Horton, \& Joseph, 2008) and therefore the methods and goals of individuals' psychosocial adaptations (i.e., the effectiveness of emotional regulation strategies). Mesquita, De Leersnyder, and Albert, (2014) note, "that the endpoints of emotion regulation in each culture are those that match the culture's valued ideas and norms about how to be a good person and how to relate to others" (p. 284). The emotional regulation strategies used by individuals may be the same across cultures, but their particular application will be dependent on culturally-sensitive situations.

Van Ijzendoorn and Sagi-Schwartz (2008) in a review of multiple cross cultural attachment studies found strong evidence for the universality of the three major attachment styles (avoidant, secure, and anxious) as well as the normative hypothesis - that secure attachment is preferable and most adaptive. They found moderate support for the relationships between parental sensitivity and secure attachment styles and sparse research suggesting that secure attachment predicts future competence. The universality of secure attachment as adaptive suggests that the emotional regulation that comes from the balanced arousal of secure attachment behaviors may also be common across cultures.

Given the universality of attachment and the centrality of emotional regulation in cultural adaptation, the current study aims to examine these factors in relation to psychopathology symptoms. In particular, the questions are which attachment styles and what specific aspects of emotion regulation correspond to the symptoms of psychopathology across the two cultures. An understanding of these relationships can have important implications for clinical intervention and for cross cultural adaptations in assessment and therapy.

\section{Method}

\section{Participants}

The total number of participants was 407 and consisted of two samples of students from universities in Turkey $(N=264)$ and the USA $(N=143)$. Gender differences in the Turkish sample included males $=76(29 \%)$ and females $=188(71 \%)$ and in American sample were males $=42(29 \%)$ and females $=101(71 \%)$. Ages ranged in the Turkish sample from 18 to 28 with a mean age of $19.8(s . d .=2.0)$ and in the USA sample from 18 to 32 with a mean age of $22.5(s . d .=3.3)$.

\section{Measures}

Experience in Close Relationship Scale (ECRS). Attachment was measured by the ECRS (Fraley, Waller, \& Brennan, 2000) which is a 36 item self-report measure that consists of anxiety and avoidance 
subscales with 18 items each. Items are rated on a 7-point Likert scale ranging from 1 ("Strongly disagree") to 7 ("Strongly agree") according to how well the item describe participants typical feelings in romantic relationships. The Anxiety Subscale assesses preoccupation with abandonment and rejection. The Avoidance Subscale assesses fear of intimacy and getting close to others. The higher scores on each subscale relate to a greater degree of avoidant and anxiety attachment levels. Secure attachment is represented by low scores on both subscales. The reliability and validity of the ECRS in English were tested by Fraley et al. (2000) who reported the Cronbach's alpha of 0.93 for the Avoidance subscale scale and 0.95 for the Anxiety subscale. The Turkish version of the ECRS was e-tested by Selcuk, Gunaydin, Sumer, and Uysal (2005) with the Cronbach's alpha of 0.90 for the Avoidance subscale scale and 0.86 for the Anxiety subscale.

Difficulties in Emotion Regulation Scale (DERS). The DERS (Graz \& Roemer, 2004) is a self-report measure that includes 36 items with a 5-point Likert scale ranging from 1 ("Almost never") to 5 ("Almost always"). The DERS includes six subscales: (a) nonacceptance of emotional responses; (b) difficulty engaging in goal-directed behavior; (c) impulse control difficulties; (d) lack of emotional awareness; (e) limited access to emotion regulation strategies; and (f) lack of emotional clarity. The reliability and validity of the ECRS in English were tested by Graz and Roemer (2004). The Cronbach alpha was 0.93 for the overall scale with subscale alphas ranging from 0.80 to 0.98 . Ruganc1 and Gençöz (2010) validated the Turkish version of the DERS and reported a Cronbach's alpha of 0.94 for the overall measure and subscale alphas between 0.75 and 0.90

Symptom Checklist-90. Psychopathological symptoms were measured by the Symptom Checklist-90 (SCL90-R: Derogatis, 1983) which is a 90 item self-report measure. The items are rated on a 5-point Likert-type scale ranging from 0 ("Not at all") to 4 ("Extremely") according to the degree that symptoms have bothered or distressed participant during the past four weeks. The SCL90-R includes ten subscales: Somatization, Obsessive-Compulsive, Interpersonal Sensitivity, Depression, Anxiety, Hostility, Phobias, Paranoid Thinking, Psychotism, and Other Symptoms. Since the last scale is heterogeneous and does not represent a particular cluster of psychopathology symptoms it was not used in the analysis. The reliability and validity of the SCL90-R in a USA sample was tested by Derogatis (1983) with Cronbach alpha coefficients for the scales ranging between 0.77 and 0.90 . The Turkish version of the SCL-90 was tested by Dağ (1991) who reported Cronbach's alphas ranging between 0.78 and 0.90 .

Demographic questionnaire. This questionnaire was designed by authors to obtain demographic information on gender, age, college major, and parents' education level.

\section{Procedure}

The measurement instruments were administrated to small groups of volunteer university students in random order to reduce response sets. Participants completed the consent form ensuring anonymity and confidentiality of the data. There was no time limitation and the participants completed all of questionnaires in approximately 40 minutes.

\section{Results}

The means and standard deviations for the measures and the $t$-test comparisons are provided in Table1. The Turkish sample scored higher on the Anxiety and Avoidant subscales of the ECRS, on three of the six subscales of the DERS and on the nine subscales of the SCL-90. 
Each of the nine subscales of SCL-90 was examined separately to determine the specific relationship of the psychopathology symptom clusters to the independent variables. Demographic variables were entered in block 1, the two attachment variables in block 2, and the six emotional regulation variables in block 3 .

As can be seen from Table 2, several family variables correlated with the psychopathology symptoms in the Turkish sample. Father's educational level accounted for variance in Somatization, Interpersonal Sensitivity, Depression, Anxiety and Psychoticism while mother's educational level accounted for Obsessive-Compulsion. Gender accounted for variance in Somatization, Obsessive Compulsion, Interpersonal Sensitivity, and Depression. Other family demographics were birth order for Hostility symptoms and number of siblings for Phobic Anxiety. Age correlated with Somatization.

Anxious attachment style accounted for variance in all nine psychopathology subscales. Avoidant style only correlated with Interpersonal Sensitivity. For the emotional regulation variables, one of the six DERS subscales-Lack of Strategies accounted for variance in all nine psychopathology subscales. Difficulties in impulse control correlated with Hostility.

In the USA sample (see Table 3) by contrast, the major demographic variable was age that accounted for variance in all nine psychopathology symptom subscales. Mother's educational level corresponded with the psychopathology symptom of Anxiety. Similarly, anxious attachment style accounted for variance in all nine psychopathology symptom subscales with Avoidant correlating for one psychopathology subscale (Anxiety). Lack of strategies likewise correlated with all nine psychopathology symptom subscales.

Table 1

Means, (Standard Deviations) and T-Tests for Attachment, Emotional Regulation and Psychopathology Symptoms in Turkish and USA Samples

\begin{tabular}{llll}
\hline & Turkish sample & USA sample & $t$-values \\
\hline Attachment (ECRS) & & & \\
\hline Anxiety level & $66.20(16.80)$ & $49.85(22.57)$ & $3.09^{* * *}$ \\
Avoidance level & $63.62(17.97)$ & $55.23(23.65)$ & $3.91^{* * *}$ \\
Emotion regulation (DERS) & & & \\
Clarity & $17.54(3.91)$ & $16.95(2.65)$ & 1.59 \\
Awareness & $21.65(3.89)$ & $21.74(4.91)$ & 0.20 \\
Impulse & $15.01(5.30)$ & $11.75(4.79)$ & $6.11^{* * *}$ \\
Nonacceptance & $12.88(5.04)$ & $12.10(5.17)$ & 1.40 \\
Goal & $16.94(4.39)$ & $14.80(5.01)$ & $4.46^{* * *}$ \\
Strategies & $19.58(6.79)$ & $15.81(6.81)$ & $5.50^{* * *}$ \\
\hline Psychopathology (SCL-90) & & & $5.02^{* * *}$ \\
\hline Somatization & $13.30(9.45)$ & $8.42(9.04)$ & $5.55^{* * *}$ \\
Obsessive-compulsive & $16.03(7.62)$ & $11.43(8.51)$ & $5.76^{* * *}$ \\
Interpersonal sensitivity & $12.61(7.47)$ & $8.14(7.38)$ & $4.70^{* * *}$ \\
Depression & $18.08(10.98)$ & $12.74(10.72)$ & $4.30^{* * *}$ \\
Anxiety & $10.75(7.6 .2)$ & $7.35(7.44)$ & $4.00^{* * *}$ \\
Hostility & $6.62(5.45)$ & $4.48(4.41)$ & $4.70^{* * *}$ \\
Phobic anxiety & $5.42(5.28)$ & $2.99(4.24)$ & $5.65^{* * *}$ \\
Paranoid ideation & $7.91(4.79)$ & $5.02(5.09)$ & $5.72^{* * *}$ \\
Psychoticism & $9.55(7.10)$ & $5.40(6.85)$ & \\
\hline
\end{tabular}

Note. ${ }^{* * *} p<0.001$. 
Table 2

\section{Regression Analysis for Turkish Sample}

\begin{tabular}{|c|c|c|c|c|c|c|c|}
\hline Predicted variable & Order of entry & Variables in the set & $F$-change & $T$ & Beta & $\begin{array}{l}\text { Partial } \\
\text { correlation }\end{array}$ & $R$ \\
\hline \multirow{5}{*}{ Somatization } & Step 1 & 1. Father Edu. Level & $6.21^{*}$ & $-2.49^{*}$ & -0.16 & -0.16 & 0.02 \\
\hline & & 2. Gender & $6.26^{* *}$ & $-2.48^{*}$ & -0.15 & -0.16 & 0.05 \\
\hline & & 3. Age & $5.76^{* * *}$ & $2.13^{*}$ & 0.13 & 0.13 & 0.07 \\
\hline & Step 2 & 4. Anxiety A. Level & $5.40^{* * *}$ & $2.02^{*}$ & 0.13 & 0.14 & 0.09 \\
\hline & Step 3 & 5. Lack of Strategies & $9.26^{* * *}$ & $4.76^{* * *}$ & 0.31 & 0.32 & 0.17 \\
\hline \multirow{4}{*}{$\begin{array}{l}\text { Obsessive } \\
\text { compulsive }\end{array}$} & Step 1 & 1. Mother Edu. Level & $4.46^{*}$ & $-2.11^{*}$ & -0.14 & -0.13 & 0.02 \\
\hline & & 2. Gender & $4.40^{*}$ & $-2.07^{*}$ & -0.13 & -0.13 & 0.04 \\
\hline & Step 2 & 3. Anxiety A. Level & $9.51^{* * *}$ & $4.37^{* * *}$ & 0.27 & 0.28 & 0.11 \\
\hline & Step 3 & 4. Lack of Strategies & $26.01^{* * *}$ & $8.21^{* * *}$ & 0.48 & 0.47 & 0.31 \\
\hline \multirow{5}{*}{$\begin{array}{l}\text { Interpersonal } \\
\text { sensivity }\end{array}$} & Step 1 & 1. Father Edu. Level & $7.21^{*}$ & $-2.68^{*}$ & -0.17 & -0.16 & 0.03 \\
\hline & & 2. Gender & $7.14^{* * *}$ & $-2.62^{*}$ & -0.16 & -0.16 & 0.05 \\
\hline & Step 2 & 3. Anxiety A. Level & $16.37^{* * *}$ & $5.74^{* * *}$ & 0.35 & 0.34 & 0.17 \\
\hline & & 4. Avoidance A. Level & $13.56^{* * *}$ & $2.14^{*}$ & 0.14 & 0.14 & 0.19 \\
\hline & Step 3 & 5. Lack of Strategies & $22.77^{* * *}$ & $6.97^{* * *}$ & 0.41 & 0.41 & 0.33 \\
\hline \multirow{4}{*}{ Depression } & Step 1 & 1. Gender & $10.60^{* *}$ & $-3.26^{* *}$ & -0.21 & -0.20 & 0.04 \\
\hline & & 2. Father Edu. Level & $9.16^{* * *}$ & $-2.73^{* *}$ & -0.17 & -0.18 & 0.06 \\
\hline & Step 2 & 3. Anxiety A. Level & $17.70^{* * *}$ & $5.69^{* * *}$ & 0.34 & 0.34 & 0.19 \\
\hline & Step 3 & 5. Lack of Strategies & $42.44^{* * *}$ & $9.77^{* * *}$ & 0.53 & 0.53 & 0.42 \\
\hline \multirow{3}{*}{ Anxiety } & Step 1 & 1. Father Edu. Level & $7.17^{* *}$ & $-2.68^{* *}$ & -0.17 & -0.17 & 0.03 \\
\hline & Step 2 & 2. Anxiety A. Level & $7.41^{* *}$ & $2.73^{* *}$ & 0.17 & 0.17 & 0.06 \\
\hline & Step 3 & 3. Lack of Strategies & $29.82^{* * *}$ & $8.38^{* * *}$ & 0.50 & 0.51 & 0.28 \\
\hline \multirow{4}{*}{ Hostility } & Step 1 & 1. Birth Order & $10.72^{* *}$ & $3.27^{* *}$ & 0.21 & 0.20 & 0.04 \\
\hline & Step 2 & 2. Anxiety A. Level & $11.51^{* * *}$ & $3.43^{* *}$ & 0.22 & 0.22 & 0.09 \\
\hline & Step 3 & 3. Lack of Strategies & $24.85^{* * *}$ & $6.85^{* * *}$ & 0.42 & 0.43 & 0.24 \\
\hline & & 4. Impulse & $19.95^{* * *}$ & $2.05^{*}$ & 0.19 & 0.19 & 0.25 \\
\hline \multirow{3}{*}{ Phobic anxiety } & Step 1 & 1. Sibling number & $19.39^{* * *}$ & $4.40^{* * *}$ & 0.28 & 0.28 & 0.08 \\
\hline & Step 2 & 2. Anxiety A. Level & $16.37^{*}$ & $3.53^{* *}$ & 0.22 & 0.21 & 0.12 \\
\hline & Step 3 & 3. Lack of Strategies & $29.66^{* * *}$ & $7.04^{* * *}$ & 0.42 & 0.43 & 0.28 \\
\hline \multirow{2}{*}{ Paranoid ideation } & Step 2 & 1. Anxiety A. Level & $26.38^{* * *}$ & $5.14^{* * *}$ & 0.32 & 0.31 & 0.10 \\
\hline & Step 3 & 2. Lack of Strategies & $31.08^{* * *}$ & $5.69^{* * *}$ & 0.35 & 0.35 & 0.21 \\
\hline \multirow{3}{*}{ Psychoticism } & Step 1 & 1. Father Edu. Level & $12.07^{* *}$ & $-3.47^{* *}$ & -0.22 & -0.22 & 0.05 \\
\hline & Step 2 & 2. Anxiety A. Level & $10.61^{* * *}$ & $2.95^{* *}$ & 0.18 & 0.19 & 0.08 \\
\hline & Step 3 & 3. Lack of Strategies & $26.20^{* * *}$ & $7.26^{* * *}$ & 0.44 & 0.44 & 0.25 \\
\hline
\end{tabular}

Note. ${ }^{*} p<0.05,{ }^{* *} p<0.01,{ }^{* * *} p<0.001$.

Table 3

Regression Analysis Report for American Sample

\begin{tabular}{|c|c|c|c|c|c|c|c|}
\hline Predicted variable & Order of entry & Variables in the set & $F$ & $T$ & Beta & $\begin{array}{l}\text { Partial } \\
\text { correlation }\end{array}$ & $R$ \\
\hline \multirow{3}{*}{ Somatization } & Step 1 & 1. Age & $8.44^{* *}$ & $-2.91^{* *}$ & -0.29 & -0.29 & 0.07 \\
\hline & Step 2 & 2. Anxiety A. Level & $12.15^{* * *}$ & $3.85^{* * *}$ & 0.33 & 0.33 & 0.18 \\
\hline & Step 3 & 3. Lack of Strategies & $12.13^{* * *}$ & $3.18^{* *}$ & 0.32 & 0.33 & 0.25 \\
\hline \multirow{3}{*}{$\begin{array}{l}\text { Obsessive } \\
\text { compulsive }\end{array}$} & Step 1 & 1. Age & $4.25^{*}$ & $-2.06^{*}$ & -0.19 & -0.20 & 0.04 \\
\hline & Step 2 & 2. Anxiety A. Level & $11.40^{* * *}$ & $4.23^{* * *}$ & 0.37 & 0.37 & 0.17 \\
\hline & Step 3 & 3. Lack of Strategies & $11.95^{* * *}$ & $3.32^{* *}$ & 0.29 & 0.29 & 0.25 \\
\hline
\end{tabular}


Table 3 continued

\begin{tabular}{|c|c|c|c|c|c|c|c|}
\hline Predicted variable & Order of entry & Variables in the set & $F$ & $T$ & Beta & $\begin{array}{l}\text { Partial } \\
\text { correlation }\end{array}$ & $R$ \\
\hline \multirow{3}{*}{$\begin{array}{l}\text { Interpersonal } \\
\text { sensivity }\end{array}$} & Step 2 & 2. Anxiety A. Level & $31.86^{* * *}$ & $5.64^{* * *}$ & 0.47 & 0.48 & 0.22 \\
\hline & Step 3 & 3. Lack of Strategies & $24.59^{* * *}$ & $3.70^{* * *}$ & 0.35 & 0.35 & 0.31 \\
\hline & Step 1 & 1. Age & $5.97^{*}$ & $-2.44^{* * *}$ & -0.23 & -0.23 & 0.05 \\
\hline \multirow[t]{4}{*}{ Depression } & Step 2 & 2. Anxiety A. Level & $28.76^{* * *}$ & $7.00^{* * *}$ & 0.54 & 0.53 & 0.34 \\
\hline & Step 3 & 3. Lack of Strategies & $24.86^{* * *}$ & $3.40^{* *}$ & 0.31 & 0.31 & 0.40 \\
\hline & Step 1 & 1. Age & $5.86^{*}$ & $-2.42^{*}$ & -0.22 & -0.21 & 0.05 \\
\hline & & 2. Mother Edu. Level & $5.64^{* *}$ & $2.28^{*}$ & 0.21 & 0.21 & 0.09 \\
\hline \multirow[t]{4}{*}{ Anxiety } & Step 2 & 3. Anxiety A. Level & $15.10^{* * *}$ & $5.57^{* * *}$ & 0.49 & 0.48 & 0.29 \\
\hline & & 4. Avoidance A. Level & $12.75^{* * *}$ & $-2.06^{*}$ & -0.18 & -0.19 & 0.32 \\
\hline & Step 3 & 5. Lack of Strategies & $14.05^{* * *}$ & $3.68^{* * *}$ & 0.34 & 0.34 & 0.39 \\
\hline & Step 1 & 1. Age & $6.01^{*}$ & $-2.45^{*}$ & -0.23 & -0.24 & 0.05 \\
\hline \multirow[t]{3}{*}{ Hostility } & Step 2 & 2. Anxiety A. Level & $9.98^{* * *}$ & $3.64^{* * *}$ & 0.32 & 0.32 & 0.15 \\
\hline & Step 3 & 3. Lack of Strategies & $8.86^{* * *}$ & $2.41^{*}$ & 0.25 & 0.25 & 0.20 \\
\hline & Step 1 & 1. Age & $7.80^{* *}$ & $-2.79^{* *}$ & -0.26 & -0.26 & 0.06 \\
\hline \multirow[t]{3}{*}{ Phobic anxiety } & Step 2 & 2. Anxiety A. Level & $13.98^{* * *}$ & $4.35^{* * *}$ & 0.37 & 0.36 & 0.20 \\
\hline & Step 3 & 3. Lack of Strategies & $14.45^{* * *}$ & $3.54^{* *}$ & 0.35 & 0.35 & 0.28 \\
\hline & Step 1 & 1. Age & $5.58^{*}$ & $-2.36^{*}$ & -0.22 & -0.22 & 0.05 \\
\hline \multirow{3}{*}{ Paranoid ideation } & Step 2 & 2. Anxiety A. Level & $13.61^{* * *}$ & $4.55^{* * *}$ & 0.39 & 0.39 & 0.20 \\
\hline & Step 3 & 3. Lack of Strategies & $11.30^{* * *}$ & $2.36^{*}$ & 0.21 & 0.22 & 0.24 \\
\hline & Step 1 & 1. Age & $5.77^{*}$ & $-2.40^{* *}$ & -0.22 & -0.22 & 0.05 \\
\hline \multirow[t]{2}{*}{ Psychoticism } & Step 2 & 2. Anxiety A. Level & $35.62^{* * *}$ & $7.89^{* * *}$ & 0.59 & 0.58 & 0.39 \\
\hline & Step 3 & 3. Lack of Strategies & $34.15^{* * *}$ & $4.40^{* * *}$ & 0.37 & 0.21 & 0.48 \\
\hline
\end{tabular}

Note. ${ }^{*} p<0.05,{ }^{* *} p<0.01,{ }^{* * *} p<0.001$.

\section{Discussion}

The universality of attachment styles and emotional regulation across cultural contexts extends to their relationship to psychopathology. Despite consistently higher scores of the Turkish sample on almost all measures, the predictive relationships with psychopathology were the same in both groups. Anxious attachment predicted all nine clusters of psychopathology symptoms. One major deficit in emotional regulation - lack of strategies, above the other deficits measured on the DERS, consistently predicted psychopathology symptoms in both samples. Thus the findings suggest that the anxiety created by preoccupation with abandonment, when coupled with poor strategies for regulating that anxiety, leads to the development of psychopathological symptoms.

Shaver and Mikulincer (2014) described the relationship between attachment styles and emotional regulation. The deactivation of attachment strategies (avoidant style) interferes with emotional regulation due to the suppression or denial of emotions and a reliance on over-estimated beliefs of superiority and competence. By contrast, the hyper-activation of attachment strategies (anxious style) involves excessive rumination on conflicted emotions, a preoccupation with inconsistently available attachment figures, and an investment in expressing one's neediness. The current study indicates that the anxious style but not the avoidant style is predictive of psychopathology in most cases. This finding may be due to anxiously attached individuals' hyper-activate preoccupation with negative emotions and mentally linking negative emotions or thoughts with a whole association of other negative emotions and thoughts (Shaver \& Mikulincer, 2002). The excessive 
preoccupation with negative emotions can result in a greater range of experienced and reported symptoms and lower estimates of one's coping capacity (Shaver \& Mikulincer, 2014). Avoidant attached individuals will suppress emotions and present a demeanor of strength and competence which might influence their own reporting of symptoms and/or their recognition of signs of psychopathology in themselves. The excessive attention to fear and other negative emotions characteristic of anxious attachment then, seems to increase the experience and reporting of psychopathological symptoms more so than the dismissive downplaying of emotions in general as found in avoidant attachment.

Both deactivation and hyper-activation of attachment processes are types of emotional regulation and can relate to the five categories of emotional regulation strategies as described by Gross and Thompson (2007) which include situation selection, situation modification, attentional deployment, cognitive change, and response modulation. Lack of effective regulation strategies may have a greater impact on individuals with anxious attachment due to the over-involvement and preoccupation with emotions. By contrast the avoidant style itself allows individuals to manage emotions by dismissing or denying them. Poorly modulated emotions in general appear to relate to symptoms of psychopathology but become stronger predictors when occurring in the framework of an anxious attachment style.

Emotional experiences and emotional regulation occur in cultural contexts. "Cultural models (of self and relationships) are apparent in the activation of responses for every facet of the emotion process through modulation of the desirability and undesirability salience of each potential response" (Mesquita \& Albert, 2007, p. 490). Sociocultural context determine the meanings of behaviors and stimuli in situations and therefore the resulting emotional processes. Cultural expectations also influence the methods of emotional regulation and expression. While the norms and expectations for emotional regulation may differ between Turkey and the USA, the needs to adapt and to fit in the respective cultural frames are the same. Ineffective emotional regulation strategies (i.e., strategies that are not effective within a specific cultural setting) will lead to discord, relational and social dissonance, and disequilibrium in the person-environment balance. Such an imbalance can transcend cultural differences in conceptualizations of psychopathology, that is, dysregulated emotions (specific to a given cultural norm) reduce adaptation to the socio-cultural environment and will relate to increased potential for psychopathology.

The influence of the collectivistic frame of the Turkish culture becomes apparent with the comparison of the significant demographic variables. Father's educational level predicted five clusters of symptoms and mother's educational predicted one. Gender predicted four clusters while birth order and number of siblings each predicted one. Parents' education likely parallels socio-economic status and may influence the quality of the family system. Gender role expectations are likely more significant in Turkish society than they would be in the USA. Taken as a group, these family and gender factors support the notion of collectivistic, interdependent dynamics playing a role in the formation of psychopathology for the Turkish sample. The USA sample, resting within an individualistic society only had one significant family demographic (mother's educational level) for the anxiety cluster of symptoms.

Clinical applications of these findings must consider the importance and universality of attachment styles and emotional regulation deficits in predicting psychopathology symptoms across the two countries. While the role of demographic variables in predicting psychopathology was small, it highlights the importance of considering the interdependent structures of collectivistic societies in understanding relationships, cultural norms and expectations. Cultural frames shape the construction, expression, and regulation of emotions 
(Shweder, Haidt, Horton, \& Joseph, 2008) as well as the conceptualization and reactions to various forms of psychopathology. The current study suggests that basic psychological structures (i.e., attachment) and adaptive capacities (i.e., emotional regulation) can be applied in clinical work across individualistic and collectivistic cultures, however the role of culture in ascribing meaning to the particular experience of individual patients must be considered.

\section{References}

Allen, J. P. (2008). The attachment system in adolescents. In J. Cassidy \& P. R. Shaver (Eds.), Handbook of attachment: Theory, research and clinical applications (2nd Ed., pp. 419-435). New York: Guilford.

Appleton, A. A., \& Kubzansky, L. D. (2014). Emotional regulation and cardiovascular disease risk. In J. Gross (Ed.), Handbook of emotion regulation (2nd Ed., pp. 596-612). New York: Guilford.

Bretherton, I., \& Munholland, K. A. (2008). Internal working models in attachment relationships: Elaborating a central construct in attachment theory. In J. Cassidy, \& P. R. Shaver (Eds.), Handbook of attachment: Theory, research and clinical applications (2nd Ed., pp. 102-127). New York: Guilford.

Bowlby, J. (1982). Attachment and loss (Vol. 1, Attachment, 2nd Ed.). New York: Basic Books.

Byng-Hall, J. (1999). Family couple therapy: Toward greater security. In J. Cassidy, \& P. R. Shaver (Eds.), Handbook of attachment: Theory, researchand clinical applications (pp. 625-645). New York: Guilford.

Campbell-Sills, L., \& Barlow, D. H. (2007). Incorporating emotion regulation into conceptualizations and treatment anxiety and mood disorders. In J. Gross (Ed.), Handbook of emotion regulation (pp. 542-559). New York: Guilford.

Campbell-Sills, L., Ellard, K. K., \& Barlow, D. H. (2014). Emotion regulation in anxiety disorders. In J. Gross (Ed.), Handbook of emotion regulation (2nd Ed., pp. 393-412). New York: Guilford.

Cassidy, J., \& Shaver, P. H. (Eds.) (2008). Handbook of Attachment: Theory, research and clinical applications (2nd Ed.). New York: Guilford.

Chen, E., \& Miller, G. E. (2014). Early-life socioeconomic status, emotion regulation, and the biological mechanisms of disease across the lifespan. In J. J. Gross (Ed.), Handbook of emotion regulation (2nd Ed., pp. 586-595). New York: Guilford.

Dağ, İ. (1991). Belirti Tarama Listesi (SCL-90-R)'nin üniversite öğrencileri için güvenirliğive geçerliği. Türk Psikiyatri Dergisi, $2(1), 5-12$.

DeKlyen, M., \& Greenberg, M. T. (2008). Attachment and psychopathology in childhood. In J. Cassidy \& P. R. Shaver (Eds.), Handbook of attachment: Theory, research and clinical applications (2nd Ed., pp. 637-665). New York: Guilford.

Derogatis, L. R. (1983). SCL-90-R Manual II. Towson, M.D.: Clinical Psychometric Research.

Diefendorff, J. M., Hall, R. J., Lord, R. G., \& Strean, M. L. (2000). Action-state orientation construct validity of a revised measure and its relationship to workrelated variables. Journal of Applied Psychology, 85, 250-263.

Deifenbach, M. A., Miller, S. M., Porter, M., Peters, E., Stefanek, M., \& Leventhal, H. (2008). Emotions and health behavior: A self-regulated perspective. In M. Lewis, J. M. Haviland, \& L. Feldman-Barrett (Eds.), Handbook of emotions (3rd Ed., pp. 645-660). New York: Guilford.

Dozier, M., Stovall-McClough, C., \& Albus, K. E. (2008). Attachment and psychopathology in adulthood. In J. Cassidy \& P. R. Shaver (Eds.), Handbook of attachment: Theory, research and clinical applications (2nd Ed., pp. 718-744). New York: Guilford.

Feeney, J. A. (2008). Adult romantic attachment: Developments in the study of couple relationships. In J. Cassidy \& P. R. Shaver (Eds.), Handbook of attachment: Theory, research and clinical applications (2nd Ed., pp. 456-481). New York: Guilford.

Feldman-Barrett, L., Wilson-Mendanhall, C. D., \& Barsalou, L. W. (2014). A psychological construction account of emotion regulation and dysregulation: The role of situated conceptualizations. In J. Gross (Ed.), Handbook ofemotion regulation (2nd Ed., pp. 447-465). New York: Guilford.

Fraley, R. C., Waller, N. G., \& Brennan, K. A. (2000). An item response theory analysis of self-report measures of adult attachment. Journal of Personality and Social Psychology, 78(2), 350-365.

Garner, P. W., \& Spears, F. M. (2000). Emotion regulation in low-income preschoolers. Social Development, 9, $246-264$.

Gratz, K. L., \& Roemer, L. (2004). Multidimensional assessment of emotion regulation and dysregulation: Development, factor structure, and initial validation of the difficulties in emotion regulation scale. Journal of Psychopathology \& Behavioral Assessment, 26(1), 41-54. 
Gross, J. J. (Ed.). (2014). Handbook of emotion regulation (2nd Ed.). New York: Guilford.

Gross, J. J., \& Levenson, R. W. (1997). Hiding feelings: The acute effects of inhibiting negative and positive emotion. Journal of Abnormal Psychology, 106(1), 95-103.

Gross, J. J., \& Thompson, R. A. (2007). Emotion Regulation: Conceptual foundations. In J. J. Gross (Ed.), Handbook of emotion regulation (pp.3-24). New York: Guilford Press.

Gunaydin, G., Selcuk, E., Sumer, N., \& Uysal, A. (2005). Ebeveyn ve Arkadaşlara Bağlanma Envanteri Kısa Formunun psikometrik açıdan değerlendirilmesi (The psychometric evaluation of a short form of Inventory of Parent and Peer Attachment). Türk Psikoloji Yazıları (Turkish Psychological Articles), 8, 13-23. (in Turkish)

Johnson, S. M. (2008). Couple and family therapy: An attachment perspective. In J. Cassidy \& P. R. Shaver (Eds.), Handbook of attachment: Theory, research and clinical applications (2nd Ed., pp. 811-829). New York: Guilford Press.

Joormann, J., \& Seimer, M. (2014). Emotion regulation in mood disorders. In J. J. Gross (Ed.), Handbook ofemotion regulation (2nd Ed., pp. 413-427). New York: Guilford Press.

Kring, A. M. (2008). Emotion disturbances as transdiagnostic processes in psychopathology. In M. Lewis, J. M. Haviland, \& L. Feldman-Barrett (Eds.), Handbook of emotions (2rd Ed., pp. 691-705). New York: Guilford Press.

Leiberman, A. F., \& Zeanah, C. H. (1999). Contributions of attachment theory to infant-parent psychotherapy and other interventions with infants and young children. In J. Cassidy and P. R. Shaver (Eds.), Handbook of attachment: Theory, research and clinical applications. New York: Guilford.

Levenson, R. W., Haase, C. M., Bloch, L., Holley, S. R., \& Seider, B. H. (2014). Emotion regulation in couples. In J. J. Gross (Ed.), Handbook ofemotion regulation (2nd Ed., pp. 267-283). New York: Guilford.

Main, M. (1990). Cross-cultural studies of attachment organization: Recent studies, changing methodologies, and the concept of conditional strategies. Human Development, 33, 48-61.

Mesquita, B., \& Albert, D. (2007). The cultural regulation of emotions. In J. J. Gross, (Ed.), Handbook of emotion regulation (pp. 486-503). NY: Guilford Press.

Mesquita, B., De Leersnyder, J., \& Albert, D. (2014). The cultural regulation of emotions. In J. J. Gross (Ed.), Handbook ofemotion regulation (2nd Ed., pp. 284-301). New York: Guilford Press.

Mikulincer, M., \& Shaver, P. R. (2007). Attachment in adulthood: Structure, dynamics and change. New York: Guilford Press.

Mikulincer, M., \& Shaver, P. R. (2008). Adult attachment and affect regulation. In J. Cassidy, \& P. R. Shaver (Eds.), Handbook of attachment: Theory, research and clinical applications (2nd Ed., pp. 503-531). New York: Guilford Press.

Mullin, B. C., \& Hinshaw, S. P. (2007). Emotion regulation and externalizing disorders in children and adolescents. In J. J. Gross (Ed.), Handbook ofemotion regulation (pp. 523-541). New York: Guilford Press.

Pennington, B. F. (2002). The development of psychopathology: Nature and nurture. New York: Guilford Press.

Ruganc1, N., \& Gençöz, T. (2010). Psychometric properties of a Turkish version of the Difficulties in Emotion Regulation Scale. Journal of Clinical Psychology, 66(4), 442-455.

Selcuk, E., Gunaydin, G., Sumer, N., \& Uysal A. (2005). Yetişkin bağlanma boyutları için yeni bir ölçüm: Yakın İlişkilerde Yaşantılar Envanteri-II'nin Türk örnekleminde psikometrik açıdan değerlendirilmesi (A new measure for adult attachment styles: The psychometric evaluation of Experiences in Close Relationships-Revised (ECR-R) on a Turkish sample). Türk Psikoloji Yazılarl (Turkish Psychological Articles), 8, 1-11. (in Turkish)

Shaver, P. R., \& Mikulincer, M. (2002). Attachment-related psychodynamics. Attachment and Human Development, 4, $133-161$.

Shaver, P. R., \& Mikulincer, M. (2014). Adult attachment and emotion regulation. In J. J. Gross (Ed.), Handbook of emotion regulation (2nd Ed., pp. 237-250). New York: Guilford Press.

Slade, A. (2008). The implications of attachment theory and research for adult psychotherapy: Research and clinical perspectives. In J. Cassidy \& P. R. Shaver (Eds.), Handbook of attachment: Theory, research and clinical applications (2nd Ed., pp. 762-782). New York: Guilford Press.

Shweder, R. A., Haidt, J., Horton, R., \& Joseph, C. (2008). The cultural psychology of the emotions: Ancient and renewed. In M. Lewis, J. M. Haviland, \& L. Feldman-Barrett (Eds.), Handbook of emotions (3rd Ed., pp. 409-427). New York: Guilford Press.

Van Ijzendoorn, M. H., \& Sagi-Schwartz, A. (2008). Cross-cultural patterns of attachment: Universal and contextual dimensions. In J. Cassidy \& P.R. Shaver (Eds.), Handbook of attachment: Theory, research and clinical applications (2nd Ed., pp. 880-905). New York: Guilford Press. 